\title{
The landscape pattern analysis of DaLonghu Wetland Park in XuZhou
}

\section{city ,China}

\author{
Xuehong $\operatorname{Tan}^{1, \mathrm{a}} \mathrm{Ye} \mathrm{Li}^{1, \mathrm{~b}}$ Xiaomin $\mathrm{Ma}^{1, \mathrm{c}}$ \\ ${ }^{1}$ Xuzhou Institute of Technology, Xuzhou, JiangSu, 221008

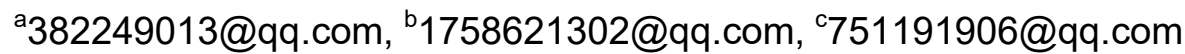

\section{Keywords: Dalonghu, wetland park, pattern analysis}

\begin{abstract}
On the basis of classifying the landscape elements, the landscape pattern of the Dalonghu wetland park was analyzed with the principle of landscape ecology in this paper, The results showed that:(1) The landscape diversity of Dalonghu wetland park was high, but the distribution of the overall landscape factors was uneven. Water patches and green patches controlled the overall landscape, which covered $90.11 \%$ of the park;(2) Wetland park landscape layout was reasonable. Buildings patches and rigid paving patches with strong human disturbance had small landscape area and great fragmentation, and not a threat for the protection of wetland landscape.
\end{abstract}

\section{Introduction}

As a special type of park, urban wetland park has many functions of ecological service besides the functions of natural scenery and recreation[1]. But with the development of city wetland park, there were the contradiction between wetland protection and reasonable utilization, and even some city over-used the wetland park tourism in order to pursue economic benefits, restricted the city wetland park health and sustainable development[2].

Landscape pattern refers to the spatial distribution and combination of different landscape elements, and is the basis for the study of landscape function and dynamics [3-4]. this paper analyzed Dalonghu wetland park spatial pattern by means of landscape pattern indexes, aiming at providing a theoretical basis for sustainable utilization and management of urban wetland park.

\section{The overview of the study area}

Xuzhou area is located in the northwest of Jiangsu province, and between east longitude $116^{\circ} 22$ ' - $118^{\circ} 40^{\prime}$, north latitude $33^{\circ} 43^{\prime}$ - $34^{\circ} 58^{\prime}$. The climate is affected by southeast monsoon, so Xuzhou has a warm temperate monsoon climate, the average annual rainfall is $847.9 \mathrm{~mm}$. The main terrain is the plains, which is part of the the Yellow Sea plain. There are 58 rivers, 16 reservoirs, 3 lakes and 20 coal mining subsidence areas in Xuzhou city.

The Dalonghu wetland park, formerly known as the Dalonghu reservoir, covered only 0.8 square kilometers of water. Ponds were scattered around the west, south and east dam of the reservoir. During the eleventh five-year plan period, the municipal government of xuzhou city transformed the environment of the Dalonghu reservoir and its surrounding environment. The Dalonghu reservoir has been become an urban wetland park with leisure, sightseeing, sports, fitness and ecological protection. At present, Dalonghu wetland park is the ecological core area of Xincheng district in xuzhou city . 


\section{Research data and methodology}

Data acquisition. The basic data used in this study was a Google Earth remote sensing map downloaded in March 2017 with 0.6 meters resolution. Remote sensing images were spliced and compared with the topographic map of Dalonghu wetland park after being built in ArcGIS,and we obtained the available remote sensing map. According to the regional characteristics, the manual method was selected to interpret the remote sensing map, and interpretation result was verified by field investigation, the field verification accuracy reached $95 \%$.

Classification of patch types. The analysis of landscape pattern was based on the classification of landscape. According to the land use of Dalonghu Wetland Park, the wetland park were divided into road, building, green, water, rigid pavement, sand, unused land seven patch types.

Index selection of landscape pattern analysis. Landscape indexes were quantitative indexes that could be highly concentrated in the landscape pattern, reflecting its structure and spatial configuration. The indexes included patch area, patch number, patch density, mean patch size, largest patch index, patch shape index, Shannon diversity index, Shannon evenness index and aggregation index[5]JAll landscape indexes were calculated using FRAGSTATS 3.4 software.

\section{Results and Discussio}

Landscape patch characteristics. The total area of Dalonghu wetland park was $347.265 \mathrm{hm}$, with a total of 638 patches. As shown in Tab1,the proportion of water area was the largest $(55.7709 \%)$, 193.6728hm.Water was the main component of the landscape, which also reflected the characteristics of Wetland Park. Green area was second, the total area of green was $120.3392 \mathrm{hm}$, and the area ratio was $34.3392 \%$. The two types of water and green accounted for $90.1101 \%$ of the whole park. This showed that the municipal government of xuzhou city insisted on ecological protection in planning and constructing Dalonghu wetland park, and taked into account the rational use of other functions, such as leisure and so on.

The road and rigid paving accounted for $7.2085 \%$ of the total park area.The rigid paving was connected with the road and played the role of flow distribution in the park. The road played a corridor role in the park. The main buildings included public service facilities, pavilions and clubs, and commercial buildings for leisure and shopping. There were no residential buildings in Dalonghu wetland park. There was a land that had been not yet exploited in the park, $2.4633 \mathrm{hm}$.

The number of green patches was the most(323), and the patch density was the biggest $(93.0125 / 100 \mathrm{hm})$, a lot of green space distributed around water body. There were only 14 water patches, but the average area of the water patch was $13.3377 \mathrm{hm}$. The number of rigid paving patches was 128, the patch density was second, and the average patch area was only $0.09643 \mathrm{hm}$. This showed that the degree of fragmentation of rigid pavement was larger than green and water. The maximum patch index of water was far greater than other patches, so water played a controlling role in the whole landscape. Can be seen from table 1, the road shape index was 54.7826, indicating that the roads were bent high. The three level park road was numerous, providing channels for tourists in-depth internal wetland, thus increasing the shape index of road. 
Tab1 Patch landscape pattern index

\begin{tabular}{cccccccc}
\hline Patch type & $\begin{array}{c}\text { area } \\
(\mathrm{hm})\end{array}$ & $\begin{array}{c}\text { area ratio } \\
(\%)\end{array}$ & $\begin{array}{c}\text { patch } \\
\text { number }\end{array}$ & $\begin{array}{c}\text { patch } \\
\text { density } \\
(\mathrm{A} \\
\text { /100hm) }\end{array}$ & $\begin{array}{c}\text { Mean } \\
\text { patch } \\
\text { size }(\mathrm{hm})\end{array}$ & $\begin{array}{c}\text { Largest } \\
\text { patch } \\
\text { index }\end{array}$ & $\begin{array}{c}\text { patch } \\
\text { shape } \\
\text { index }\end{array}$ \\
\hline $\begin{array}{c}\text { green } \\
\text { road }\end{array}$ & 120.3392 & 34.6534 & 323 & 93.0125 & 0.3726 & 3.1408 & 29.314 \\
$\quad 12.6955$ & 3.6559 & 69 & 19.8696 & 0.184 & 2.5507 & 54.7826 \\
rigid & 12.3369 & 3.5526 & 128 & 36.8595 & 0.0964 & 0.7574 & 22.542 \\
pavement & & & & & & & \\
water & 193.6728 & 55.7709 & 14 & 4.0315 & 13.3377 & 54.2139 & 5.5154 \\
construction & 5.2649 & 1.5161 & 67 & 19.2936 & 0.0786 & 0.2914 & 10.732 \\
sand & 0.4924 & 0.1418 & 36 & 10.3667 & 0.0137 & 0.0515 & 7.4043 \\
unused lan & 2.4633 & 0.7093 & 1 & 0.288 & 2.4633 & 0.7093 & 1.6656 \\
\hline
\end{tabular}

\section{Analysis of the overall landscape pattern.}

The overall patch density of Dalonghu wetland park was $183.7214 / 100 \mathrm{hm}$, the patch density was high, and the average patch area was less than $1 \mathrm{hm}$ (Tab2). Compared with the wetland park dominated by ecological protection, the fragmentation rate of Dalonghu wetland park was larger, which may be due to the high resolution of the remote sensing map used in this study. Table 2 showed that the Shannon diversity index and Shannon evenness index of Wetland Park were 1.0404 and 0.5346 respectively. This showed that the landscape diversity of Dalonghu wetland park was high, but the distribution of the overall landscape factors was uneven, this was consistent with the fact that the Dalonghu wetland park was controlled by water and green.Especially, the concentration of landscape water was especially obvious, therefore, the aggregation index of the whole landscape was higher, which was 98.0705.

Tab2 Overall landscape pattern index

\begin{tabular}{cccccc}
\hline & $\begin{array}{c}\text { patch } \\
\text { density } \\
(\mathrm{A} \\
/ 100 \mathrm{hm})\end{array}$ & $\begin{array}{c}\text { Mean } \\
\text { patch size } \\
(\mathrm{hm})\end{array}$ & $\begin{array}{c}\text { Shannon } \\
\text { diversity } \\
\text { index }\end{array}$ & $\begin{array}{c}\text { Shannon } \\
\text { evenness } \\
\text { index }\end{array}$ & $\begin{array}{l}\text { aggregation } \\
\text { index }\end{array}$ \\
\hline $\begin{array}{c}\text { Landscape } \\
\text { index }\end{array}$ & 183.7214 & 0.5443 & 1.0404 & 0.5346 & 98.0705 \\
\hline
\end{tabular}

\section{Conclusions}

Dalonghu wetland park had a large number of patches and high patch density, but as a whole, the water patches and green patches played controlling roles in the overall landscape. the landscape diversity of Dalonghu wetland park was high, but the distribution of the overall landscape factors was uneven. The maximum shape index of water body was 54.2139, the large water patches maintained good ecological integrity.

Building patches and rigid paving patches with strong human disturbance had small landscape area and great fragmentation, and not a threat for the protection of wetland landscape, and could increase the diversity of the landscape, providing services and convenience for visitors. 


\section{Acknowledgements}

This work was financially supported by Breeding Project of Xuzhou Institute of Technology(XKY2013105),Science and Technology Planning Projects of XuZhou City(KC15SM036).

\section{References}

[1] JianTao Lin, Yang Hu, Lei Hu.. Planning and Design for Urban Wetland Parks Based on Local Characteristics [J].China Garden, 2013,11: 104-108.

[2] Yufeng Li, Hongyu Liu, Nan Zheng, Xiao Cao. A functional classification method for examining landscape pattern of urban wetland park: a case study on Xixi Wetland Park, China [J]. Acta ecologica sinica,2011, 31(4):1021-1028.

[3] Jianwen Wang, Jihuai Wang, Jihua Wu. Analysis of Landscape Pattern of Huaxi National Urban Wetland Park:A Case Study of Huaxi National Urban Wetland Park of Guiyang City[J]. Guizhou science, 2013, 31 (6): 80-84.

[4] Fangjun Liao, Zhiming Chen, Zong-jun Liu, Yong Xie. Study on landscape patterns changes of each functional zone in Nanling National Nature Reserve in Guangdong province[J].Journal of Central South University of Forestry and Technology, 2015, 35 (9): 113-121.

[5]JinPing Guo. Landscape ecology[M]. china forestry press, 2006. 